\title{
Analisis Sifat Fisik dan Kompresibilitas Nanopowder Zinc Oxide (ZnO) sebagai Alternatif Material Amalgam
}

\author{
Nanang Qosim ${ }^{1}$, Putut Murdanto², Poppy Puspitasari ${ }^{3}$ \\ 1Departemen Teknik Mesin, Fakultas Teknik, Universitas Indonesia, Kampus Baru UI, Depok \\ 16424, Jawa Barat, Indonesia \\ 2,3Jurusan Teknik Mesin, Fakultas Teknik, Universitas Negeri Malang, Jl. Semarang 5, Malang \\ 65145, Jawa timur, Indonesia \\ Email: nanang.qosim@ui.ac.id
}

\begin{abstract}
Severe effects of the mercury use on health as an amalgam material have required an alternative material in order to eliminate it from amalgam composition. This research was conducted to analyze the physical properties and compressibility of ZnO nanopowder as an alternative amalgam material. The physical properties including morphology, dimensions, and the atomic ratio were analyzed by SEM, XRD-XRF and EDX. Further, the compressibility was conducted by using hydraulic press machine. The results showed that ZnO has particle size of $14.34 \mathrm{~nm}$ with morphology classified as nanorods. In the compressibility test, both the variation of compression loadings and holding time have brought an effect on the significant increase of ZnO nanopowder density.
\end{abstract}

Keywords: amalgam, nanopowder, ZnO, physical properties, compressibility

\section{PENDAHULUAN}

Teknologi nano merupakan salah satu kemajuan dalam ilmu material dan rekayasa yang berkembang pesat saat ini. Teknologi ini berkembang pesat seiring peningkatan pengetahuan dan pemahaman manusia dalam bidang kimia dan fisika bahan, kemajuan dalam metode pengolahan, dan juga ketersediaan peralatan canggih untuk melakukan penelitian. Teknologi ini didefinisikan sebagai suatu teknologi atau pemahaman dan kontrol materi pada dimensi dan toleransi yang berada pada kisaran 0,1$100 \mathrm{~nm}$ (dari ukuran atom sekitar panjang gelombang cahaya) [1, 2].

Zinc Oxide ( $\mathrm{ZnO}$ ) adalah material yang unik yang banyak digunakan oleh sebagian besar peneliti untuk aplikasi yang sangat luas dan beragam. ZnO memiliki berbagai jenis morfologi dan ukuran yang akan menentukan kesesuaian penggunaannya. Material ini biasa digunakan untuk zat aditif pada cat, material keramik, katalis, peralatan elektronik, optoelektronik, semikonduktor dan masih banyak lagi. Keunikan bentuk nanostruktur $\mathrm{ZnO}$ menunjukkan bahwa $\mathrm{ZnO}$ adalah material terkaya dalam keluarga nanomaterial baik dari segi struktur maupun sifat-sifatnya. Sifat-sifat nanopowder $\mathrm{ZnO}$ tergantung pada karakter morfologi dan struktur nanonya yang ditentukan dari metode sintesis yang digunakan [3, 4]. Sehingga dari deskripsi karakteristik material $\mathrm{ZnO}$ tersebut diharapkan dengan penerapan teknologi nano, ZnO memiliki kekuatan yang lebih baik dari material penambal gigi sebelumnya, di samping kelebihan $\mathrm{ZnO}$ itu sendiri yang memiliki warna yang khas putih menyerupai warna natural gigi.

\section{METODOLOGI PENELITIAN}

Sampel yang digunakan pada penelitian ini adalah nanopowder $\mathrm{ZnO}$. Karakterisasi sifat fisik yang meliputi morfologi, dimensi, dan rasio atom, masing-masing dianalisis menggunakan scanning electron microscope (SEM), $x$-ray diffraction (XRD), $x$-ray fluorescence (XRF) dan energy dispersive $x$ ray (EDX).

Pada uji kompresibilitas menggunakan mesin press hidraulik, diberlakukan variabel kontrol yang meliputi variasi pembebanan (variation of loading) yaitu sebesar 500, 1000 dan 2000 kg. Selain itu, divariasikan pula waktu tahan (dwelling time) selama proses kompresi sebesar 30,60, dan 90 detik. Lebih ringkasnya metodologi dapat disimpulkan dalam diagram alir pada Gambar 1 . 


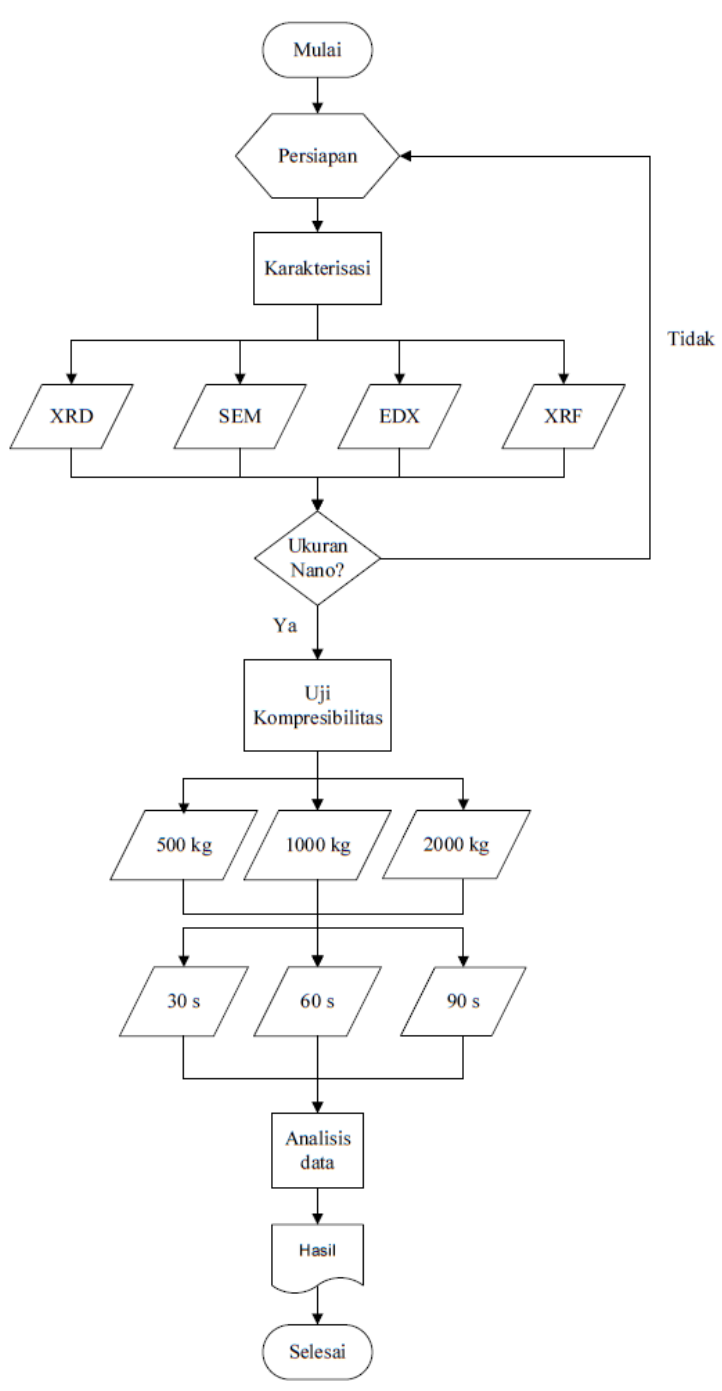

Gambar 1. Skema Prosedur Penelitian

\section{HASIL DAN PEMBAHASAN}

\section{A. Uji Karakterisasi XRD}

Serbuk nanopowder $\mathrm{ZnO}$ pada grafik hasil uji karakterisasi XRD, seperti ditampilkan pada Gambar 2, menunjukkan puncak difraksi yang identik dengan puncak difraksi standar $\mathrm{ZnO}$. Grafik hasil uji karakterisasi dengan XRD menunjukkan bahwa sampel serbuk nanopowder $\mathrm{ZnO}$ berada dalam puncak difraksi pada bidang [100], [002], dan [101] dengan struktur Hexagonal Wurtzite.

Puncak difraksi tersebut menunjukkan intensitas puncak yang sangat kuat, hal ini memberi pengertian bahwa sampel nanopowder $\mathrm{ZnO}$ tersebut memiliki kristalinitas yang tinggi. Parameter-parameter hasil uji karakterisasi XRD nanopowder ZnO disajikan dalam Tabel 1.

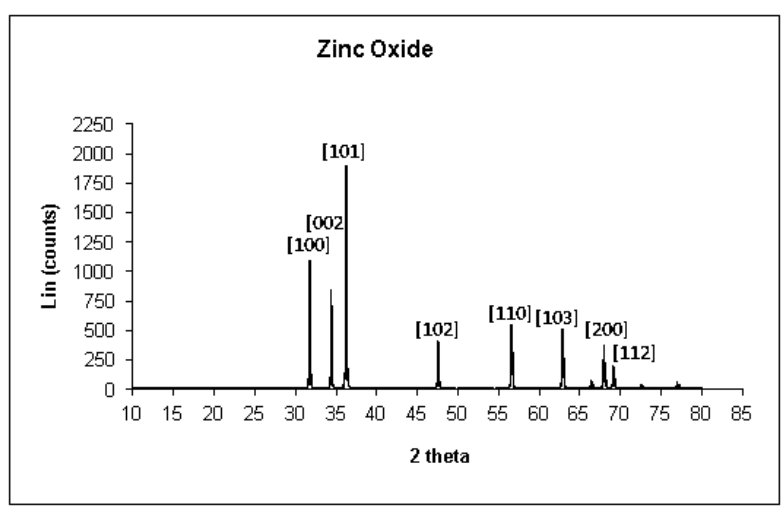

Gambar 2. Hasil Uji XRD Nanopowder ZnO

Tabel 1. Hasil XRD ZnO

\begin{tabular}{ll}
\hline \multicolumn{2}{c}{$X$-Ray Diffraction (XRD) } \\
\hline Intensitas (cps) & 1.890 \\
\hline FWHM (2-theta $\left.{ }^{\circ}\right)$ & 0.113 \\
\hline$\lambda(\AA)$ & 1.540 \\
\hline$\theta$ & $18.120^{\circ}$ \\
\hline $\mathrm{a}$ & 3.250 \\
\hline $\mathrm{b}$ & 3.250 \\
\hline $\mathrm{c}$ & 5.207 \\
\hline
\end{tabular}

Secara teoritis, ukuran partikel dari sampel serbuk $\mathrm{ZnO}$ didapatkan dengan menggunakan persamaan Scherrer. Perhitungan penentuan ukuran partikel $\mathrm{ZnO}$ berdasarkan persamaan Scherrer adalah sebagai berikut [5]:

$$
\text { Diketahui: } \begin{array}{ll}
\mathrm{K} & =0,9-1 \\
\lambda & =1,540 \AA \\
\mathrm{FWHM} & =0,113 \mathrm{cps} \\
\theta & =18,126^{\circ}
\end{array}
$$

Penentuan nilai $\beta$,

$$
\begin{aligned}
B & =\frac{F W H M \times 2 \pi}{360^{\circ}} \\
& =\frac{0,113 \times 360^{\circ}}{360^{\circ}} \\
& =0,113
\end{aligned}
$$

Persamaan Scherrer,

$$
\mathrm{D}=\frac{\mathrm{K} \lambda}{(\beta \cos \theta)}
$$




$$
\begin{aligned}
& =\frac{1 \times 1,540}{0,113\left(\cos 18,126^{\circ}\right)} \\
& =14,340
\end{aligned}
$$

Dari perhitungan tersebut dapat diketahui bahwa sampel nanopowder $\mathrm{ZnO}$ yang diuji memiliki dimensi ukuran partikel sebesar $14,340 \mathrm{~nm}$.

\section{B. Uji Karakterisasi XRF}

Uji karakterisasi XRF bertujuan untuk mengetahui persentase unit-unit material yang terkonsentrasi dalam senyawa $\mathrm{ZnO}$. Hasil uji karakterisasi XRF sampel $\mathrm{ZnO}$ disajikan dalam Tabel 2.

Tabel 2. Konsentrasi Unsur pada Senyawa Zno

\begin{tabular}{lc}
\hline \multicolumn{1}{c}{ Compound } & Conc. Unit \\
\hline Calsium $(\mathrm{Ca})$ & $0,14+/-0,01 \%$ \\
\hline Chrom $(\mathrm{Cr})$ & $0,085+/-0,001 \%$ \\
\hline Ferro $(\mathrm{Fe})$ & $0,14+/-0,008 \%$ \\
\hline Nikel $(\mathrm{Ni})$ & $0,25+/-0,05 \%$ \\
\hline Cuprum $(\mathrm{Cu})$ & $0,11+/-0,003 \%$ \\
\hline Zinc $(\mathrm{Zn})$ & $86,68+/-9,88 \%$ \\
\hline Zircon $(\mathrm{Zr})$ & $2,4+/-0,4 \%$ \\
\hline Erbium $(\mathrm{Er})$ & $0,02+/-0,005 \%$ \\
\hline Yiterbium $(\mathrm{Yb})$ & $0,51+/-0,14 \%$ \\
\hline Niobium $(\mathrm{Nb})$ & $19+/-1 \%$ \\
\hline Titanium $(\mathrm{Ti})$ & $0,035+/-0,002 \%$ \\
\hline
\end{tabular}

Hasil analisis yang tersaji dalam Tabel 2. menunjukkan bahwa di dalam sampel serbuk $\mathrm{ZnO}$ yang dikarakterisasi terkandung unsur Calsium (Ca), Chrom (Cr), Ferro (Fe), Nikel $(\mathrm{Ni})$, Cuprum $(\mathrm{Cu})$, Zircon $(\mathrm{Zr})$, Erbium $(\mathrm{Er})$, Yiterbium (Yb), Niobium ( $\mathrm{Nb}$ ), dan Titanium (Ti).

\section{Uji Karakterisasi SEM}

Morfologi dari sampel serbuk nanopowder $\mathrm{ZnO}$ dianalisis dengan menggunakan uji SEM dengan hasil pengujian ditampilkan pada Gambar 3.

Struktur nano pada gambar hasil uji karakteriasi SEM adalah cenderung tampak seperti jenis nanorods. Hal tersebut karena suhu dan waktu sintering yang cukup baik, sehingga struktur nano sampel serbuk $\mathrm{ZnO}$ memiliki struktur yang tepat dari segi bentuknya. Secara teoritis, perbedaan waktu dan suhu sintering akan menyebabkan perbedaan struktur nano serbuk $\mathrm{ZnO}$. Hal ini karena $\mathrm{ZnO}$ adalah bahan fungsional serbaguna yang memiliki berbagai kelompok morfologi seperti nanocombs, nanorings, nanohelixes, nanosprings, nanobelts, nanowires, nanorods, nanocages, dan sebagainya. Semua klasifikasi struktur nano yang unik tersebut menunjukkan bahwa $\mathrm{ZnO}$ memiliki struktur nano yang kaya baik dari sisi struktur maupun sifatnya.

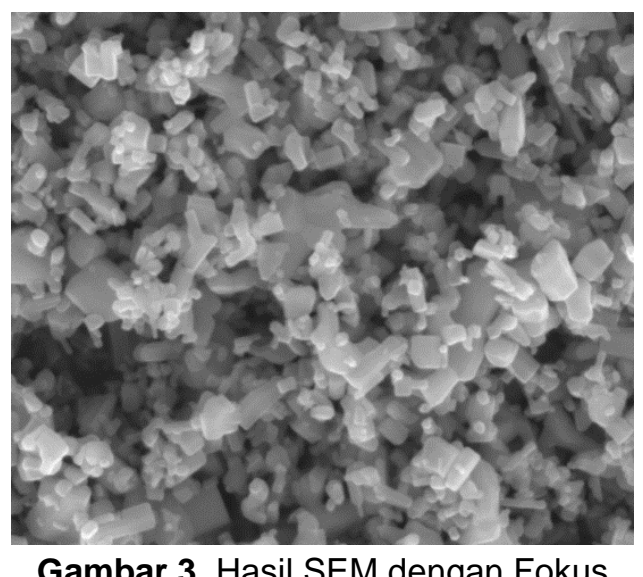

Gambar 3. Hasil SEM dengan Fokus Perbesaran $40.000 \mathrm{x}$

\section{Hasil Uji Karakterisasi EDX}

Selanjutnya dianalisis rasio persentase atom dari sampel serbuk nanopowder $\mathrm{ZnO}$ dilakukan dengan menggunakan uji karakterisasi EDX. Hasil uji karakterisasi EDX untuk serbuk nanopowder $\mathrm{ZnO}$ ditampilkan pada Gambar 4.

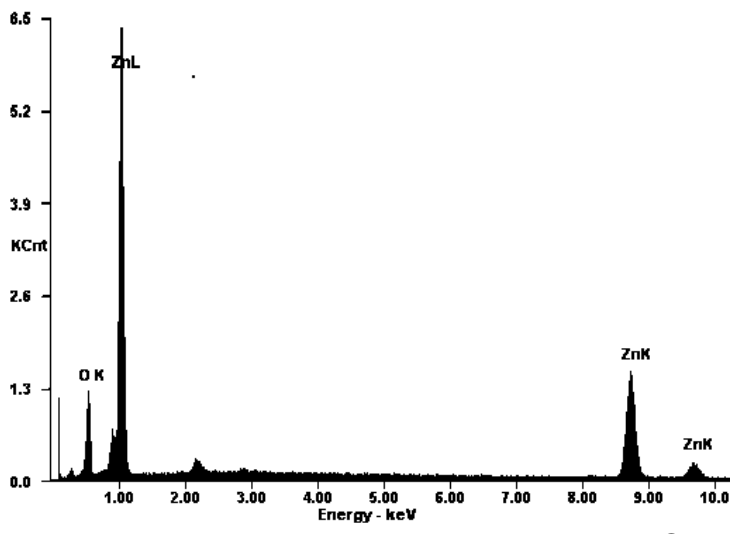

Gambar 4. Hasil EDX Nanopowder ZnO

Secara teoritis, persentase atom untuk elemen $\mathrm{ZnO}$ seharusnya dalam rasio 50:50 berdasarkan rumus kimia. Berdasarkan analisis unsur untuk sampel nanopowder $\mathrm{ZnO}$, 
memberi pengertian bahwa tidak ada penyimpangan yang terlalu besar atau signifikan dalam persentase atom zinc $(\mathrm{Zn})$ dan oxigen $(\mathrm{O})$ sesuai standar persentase deviasi elemen senyawa kimia.

Tabel 3. Persentase Unsur pada Senyawa $\mathrm{ZnO}$

\begin{tabular}{cccc}
\hline Elemen & \% Berat & \% Atom & \% Deviasi \\
\hline $\mathrm{O}$ & 13,32 & 44,06 & 11,88 \\
\hline $\mathrm{Zn}$ & 86,68 & 55,94 & 11,88 \\
\hline
\end{tabular}

Data dalam Tabel 3 menunjukkan bahwa sampel serbuk nanopowder ZnO memiliki rasio persentase atom $\mathrm{Zn}$ sebesar 55,94\% dan atom $\mathrm{O}$ sebesar 44,06\%, sehingga secara otomatis persentase penyimpangan atom (deviasi) untuk sampel $\mathrm{ZnO}$ tersebut adalah hanya sebesar $11,88 \%$.

\section{E. Uji Kompresibilitas Nanopowder ZnO}

Dari semua hasil pengujian kompresibilitas baik dengan pembebanan 500, 1000, maupun $2000 \mathrm{~kg}$, dapat menunjukkan bahwa variasi pembebanan kompresi memberikan pengaruh yang sangat signifikan terhadap peningkatan nilai rata-rata densitas kepadatan. Peningkatan tersebut secara teoritis disebabkan karena semakin besar beban kompresi yang diberikan, maka kemampuan serbuk untuk memadat semakin tinggi. Hal ini bisa diidentifiksi dari indikasi yang paling rasional secara empiris, yakni pada nilai ketebalan tablet yang dihasilkan. Semakin besar beban kompresi yang diberikan (dengan asumsi massa yang sama) maka ketebalan sampel tablet yang dihasilkan akan semakin kecil.

Kesimpulannya, semakin besar pembebanan kompresi yang diberikan, maka nilai kepadatan semakin meningkat secara signifikan. Secara terperinci, pada saat perlakuan waktu tahan sebesar 30 detik, pembebanan sebesar $500 \mathrm{~kg}$ memberikan nilai densitas kepadatan sebesar $3,112 \mathrm{~g} / \mathrm{cm}^{3}$, dan meningkat menjadi $3,307 \mathrm{~g} / \mathrm{cm}^{3}$ saat pembebanan dinaikkan sebesar $1000 \mathrm{~kg}$, selanjutnya meningkat menjadi $3,360 \mathrm{~g} / \mathrm{cm}^{3}$ saat pembebanan dinaikkan sebesar $2000 \mathrm{~kg}$. Pada waktu tahan 60 detik, pembebanan sebesar $500 \mathrm{~kg}$ memberikan densitas kepadatan sebesar $3,153 \mathrm{~g} / \mathrm{cm}^{3}$, $3,313 \mathrm{~g} / \mathrm{cm}^{3}$ untuk beban $100 \mathrm{~kg}$, dan 3,372 $\mathrm{g} / \mathrm{cm}^{3}$ untuk beban sebesar $2000 \mathrm{~kg}$. Selanjutnya saat waktu tahan 90 detik, saat pembebanan sebesar $500 \mathrm{~kg}$ nilai densitas kepadatannya adalah $3,245 \mathrm{~g} / \mathrm{cm}^{3}$, dengan beban $1000 \mathrm{~kg}$ meningkat menjadi 3,343 $\mathrm{g} / \mathrm{cm}^{3}$, selanjutnya dengan beban $2000 \mathrm{~kg}$ meningkat lagi menjadi $3,495 \mathrm{~g} / \mathrm{cm}^{3}$. Peningkatan nilai densitas kepadatan tersebut dapat dilihat dalam grafik pada Gambar 5.

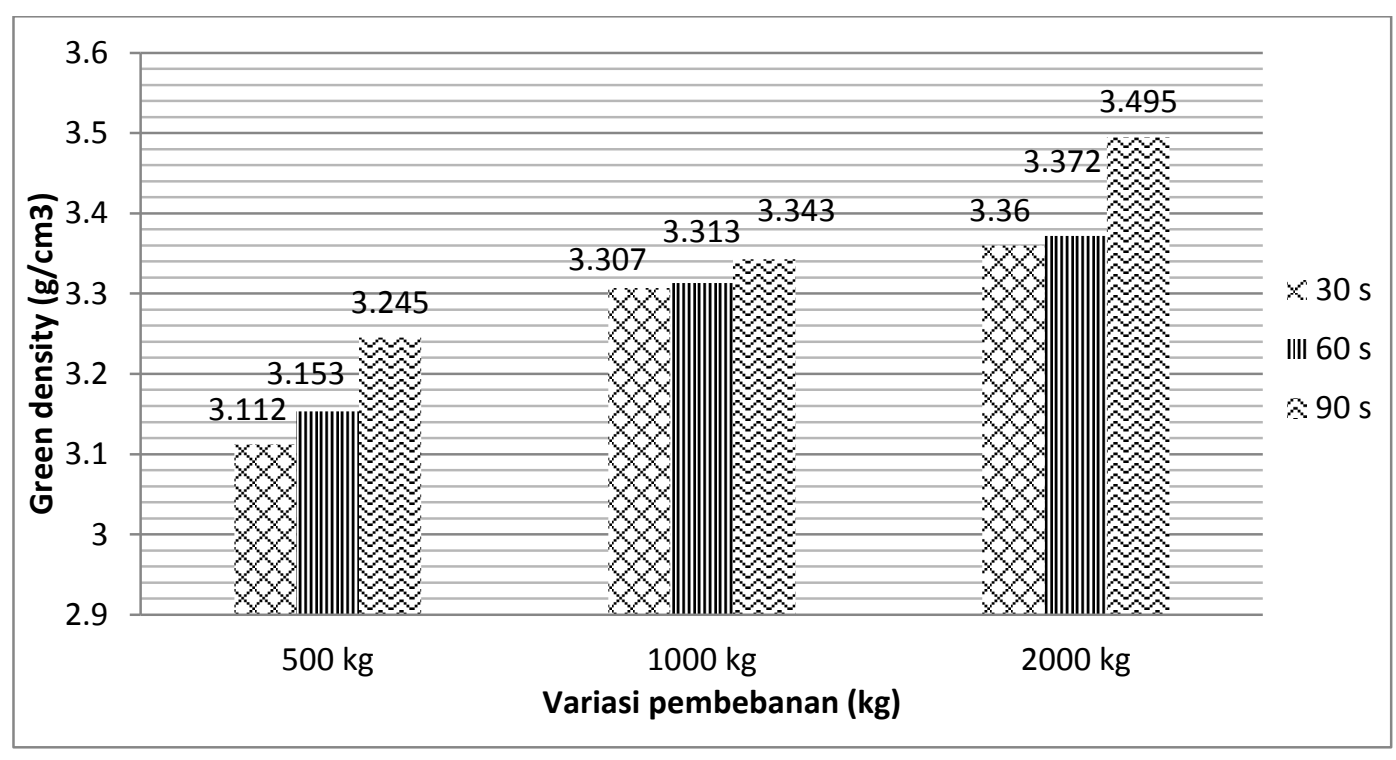

Gambar 5. Grafik Pengaruh Pembebanan terhadap Densitas Kepadatan ZnO 


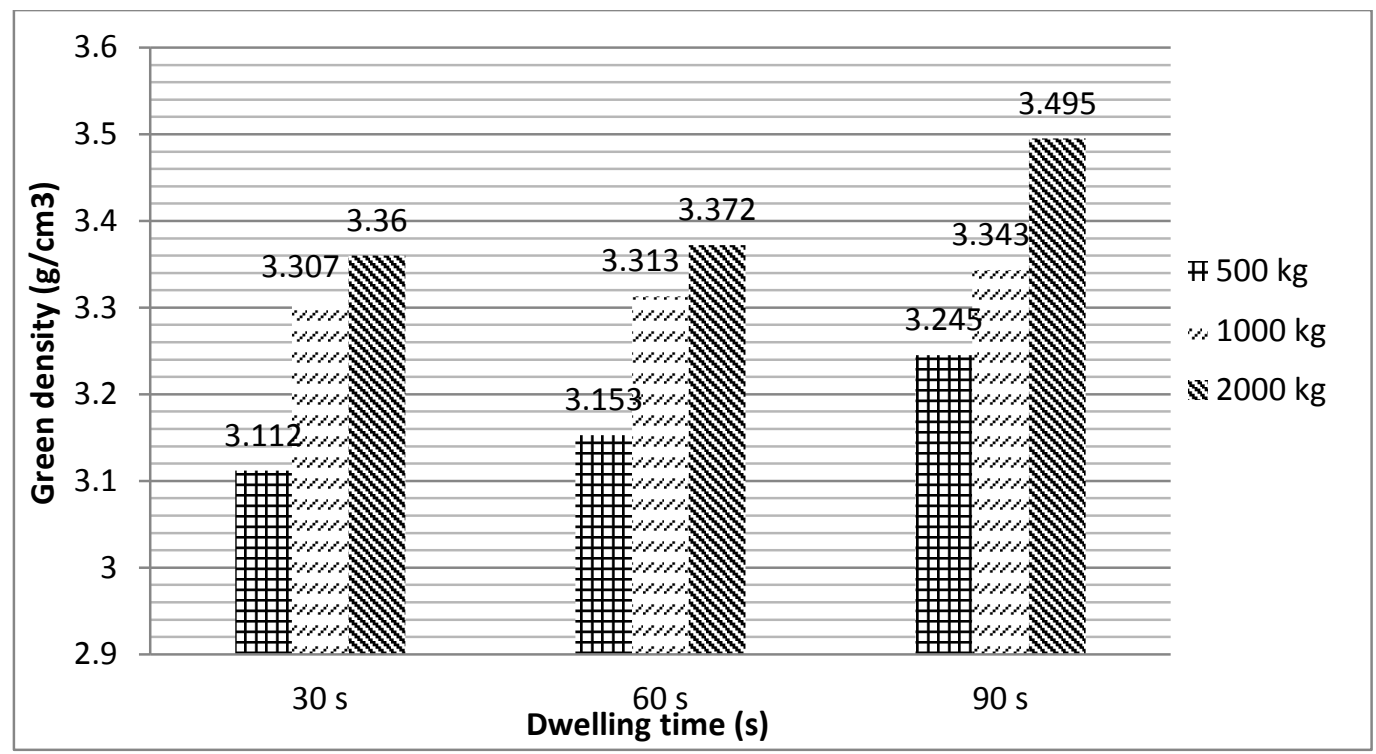

Gambar 6. Grafik Pengaruh Dwelling Time terhadap Densitas Kepadatan ZnO

Di sisi lain, perbedaan waktu tahan juga memberikan pengaruh peningkatan terhadap densitas kepadatan secara signifikan. Artinya semakin besar waktu tahan yang diberikan, maka densitas kepadatan tablet akan semakin meningkat. Berdasarkan informasi hasil pengujian, secara terperinci pada saat pembebanan sebesar $500 \mathrm{~kg}$, waktu tahan sebesar 30 detik memberikan nilai densitas kepadatan sebesar $3,112 \mathrm{~g} / \mathrm{cm}^{3}$, dan meningkat menjadi $3,153 \mathrm{~g} / \mathrm{cm}^{3}$ saat waktu tahan dinaikkan menjadi 60 detik, selanjutnya meningkat menjadi $3,245 \mathrm{~g} / \mathrm{cm}^{3}$ saat waktu tahan dinaikkan lagi menjadi 90 detik.

Selanjutnya, pada pembebanan sebesar $1000 \mathrm{~kg}$, waktu tahan sebesar 30 detik memberikan nilai densitas kepadatan sebesar $3,307 \mathrm{~g} / \mathrm{cm}^{3}$, meningkat menjadi $3,313 \mathrm{~g} / \mathrm{cm}^{3}$ saat waktu tahan dinaikkan menjadi 60 detik, dan meningkat menjadi $3,343 \mathrm{~g} / \mathrm{cm}^{3}$ saat waktu tahan dinaikkan lagi menjadi 90 detik.

Pada variasi pembebanan terakhir, saat pembebanan pada mesin press hidrolik disetting sebesar $2000 \mathrm{~kg}$, nilai densitas kepadatan tablet adalah sebesar $3,360 \mathrm{~g} / \mathrm{cm}^{3}$ saat waktu tahan yang diberikan 30 detik, nilai ini kemudian meningkat menjadi $3,372 \mathrm{~g} / \mathrm{cm}^{3}$ ketika waktu tahan ditingkatkan menjadi 60 detik, dan meningkat lagi menjadi $3,495 \mathrm{~g} / \mathrm{cm}^{3}$ ketika waktu tahan ditingkatkan menjadi 90 detik.
Peningkatan densitas kepadatan ini secara teoritis disebabkan karena pada saat diberikan waktu tahan selama periode waktu beberapa detik, menyebabkan pembebanan yang diberikan bersifat dinamis, sehingga dari pembebanan dinamis tersebut densitas kepadatan akan semakin meningkat. Hal ini ditandai dengan perubahan ketebalan tablet (dengan asumsi massa yang sama) menjadi semakin kecil.

\section{KESIMPULAN}

1) Sifat-sifat fisik nanopowder $\mathrm{ZnO}$ yang dianalisis dari hasil uji karakterisasi memiliki ukuran partikel sebesar 14,34 $\mathrm{nm}$, morfologi nanopowder $\mathrm{ZnO}$ terklasifikasi dalam jenis nanorods, serta senyawa $\mathrm{ZnO}$ memiliki rasio persentase atom zinc (Zn) sebesar $55,94 \%$ dan atom oxygen (O) sebesar $44,06 \%$, dengan persentase deviasi atom sebesar $11,88 \%$.

2) Pada pembebanan kompresi $500 \mathrm{~kg}$, densitas kepadatan rata-rata $\mathrm{ZnO}$ adalah sebesar $3,170\left(\mathrm{~g} / \mathrm{cm}^{3}\right)$, mengalami peningkatan sebesar $4,763 \%$ saat beban kompresi dinaikkan menjadi $1000 \mathrm{~kg}$, kemudian mengalami peningkatan sebesar $7,539 \%$ saat beban kompresi dinaikkan lagi menjadi $2000 \mathrm{~kg}$. Perbedaan waktu tahan juga memberikan pengaruh yang sama, pada saat waktu 
tahan sebesar 30 detik, densitas kepadatan rata-rata $\mathrm{ZnO}$ adalah sebesar 3,260 $\left(\mathrm{g} / \mathrm{cm}^{3}\right)$, saat waktu tahan 90 detik nilai densitas kepadatan tersebut mengalami peningkatan sebesar $0,583 \%$, kemudian saat waktu tahan 90 detik mengalami peningkatan lagi sebesar 3,098\%.

\section{DAFTAR PUSTAKA}

[1] Klabunde, K.J. and R. Richards, Nanoscale materials in chemistry. Vol. 1035. 2001: Wiley Online Library.

[2] Buzea, C., I.I. Pacheco, and K. Robbie, Nanomaterials and nanoparticles: Sources and toxicity. Biointerphases, 2007. 2(4): p. MR17-MR71.
[3] Bedi, P. and A. Kaur, An overview on uses of zinc oxide nanoparticles. World Journal of Pharmacy and Pharmaceutical Sciences, 2015. 4(12): p. 1177-1196.

[4] Wang, Z.L., Zinc oxide nanostructures: growth, properties and applications. Journal of physics: condensed matter, 2004. 16(25): p. R829.

[5] Smilgies, D.-M., Scherrer grain-size analysis adapted to grazing-incidence scattering with area detectors. Journal of applied crystallography, 2009. 42(6): p. 1030-1034. 